Article

\title{
The Impact of Freeze-Drying Conditions on the Physico-Chemical Properties and Bioactive Compounds of a Freeze-Dried Orange Puree
}

\author{
Marilú A. Silva-Espinoza ${ }^{1}\left(\right.$, Charfedinne Ayed ${ }^{2}$, Timothy Foster ${ }^{2}$, María del Mar Camacho $^{1}$ \\ and Nuria Martínez-Navarrete ${ }^{1, *}$ \\ 1 Food Technology Department, Food Investigation and Innovation Group, Universitat Politècnica de \\ València, Camino de Vera s/n, 46022 Valencia, Spain; masiles@doctor.upv.es (M.A.S.-E.); \\ mdmcamvi@tal.upv.es (M.d.M.C.) \\ 2 Department of Food, Nutrition and Dietetics, School of Biosciences, University of Nottingham, \\ Sutton Bonington Campus, Loughborough LE12 5RD, UK; Charfedinne.Ayed@nottingham.ac.uk (C.A.); \\ Tim.Foster@nottingham.ac.uk (T.F.) \\ * Correspondence: nmartin@tal.upv.es
}

Received: 28 November 2019; Accepted: 24 December 2019; Published: 30 December 2019

\begin{abstract}
Fruits are essential for a healthy diet, as they contribute to the prevention of cardiovascular diseases and some cancers, which is attributed to their high bioactive compound content contributing to their antioxidant capacity. Nevertheless, fruits have a short shelf life due to their high-water content, and freeze-drying is a well-known technique to preserve their nutritive quality. However, it is an expensive technology, both due to the use of low pressure and long processing time. Therefore, an optimisation of variables such as the freezing rate, working pressure and shelf temperature during freeze-drying may preserve fruit quality while reducing the time and costs. The impact of these variables on colour, porosity, mechanical properties, water content, vitamin $C$, total phenols, $\beta$-carotene, and antioxidant activity of a freeze-dried orange puree was evaluated. The results showed a great impact of pressure and shelf temperature on luminosity, chroma and water content. Vitamin $\mathrm{C}$ and $\beta$-carotene were more preserved with higher shelf temperatures (shorter times of processing) and lower pressure, respectively. The optimum freeze-drying conditions preserving the nutrients, and with an interesting structural property, perceived as a crunchy product by consumers, are low pressure $(5 \mathrm{~Pa})$ and high shelf temperature $\left(50{ }^{\circ} \mathrm{C}\right)$.
\end{abstract}

Keywords: vitamin C; total phenols; total carotenoids; antioxidant activity; colour; mechanical properties; pressure; shelf temperature; freezing rate

\section{Introduction}

It is known that there is interest in the consumption of fruits, as they are recommended as components of a healthy diet due to their contribution to the prevention of some diseases when they are consumed in adequate quantity [1,2]. This effect is attributed to their high content of bioactive compounds such as phytochemicals, some vitamins and fibre [3]. In particular, the orange and its derived products are a rich source of flavonoids (mainly hesperidin), carotenes, and vitamin C, with concentrations in the range of $15-238.8 \mathrm{mg}, 182-198 \mu \mathrm{g}$ and $43.5-50 \mathrm{mg} / 100 \mathrm{~g}$ edible fruit, respectively [4-9]. In fact, an average orange would contribute $80 \%$ of the RDA (recommended daily allowance) of vitamin C [10]. However, fruits have two main problems that affect their continuous availability, which are seasonality and short shelf life. Dehydration is one of the most common techniques used to preserve food. In addition, it also entails a reduction in the volume and weight of the product, which facilitates its transport and handling [11]. 
Freeze-drying is a dehydration technique based on the sublimation of the water present in a product, which results in a reduction of water activity and therefore the related deterioration processes to which a food is subjected [12]. The product is frozen in order to be subjected to vacuum pressure with the consequent sublimation and desorption of the water. Freeze-drying operates at low temperatures, which contributes to preserve characteristics such as taste, colour or appearance and to minimize the degradation of thermolabile compounds, many of them responsible for the aromas and nutritional value of the fruits. Thus, the final freeze-dried product is high quality as compared with other techniques of dehydration [13].

Despite the improved microbiological stability of the final product, the chemical and physical attributes may be sometimes compromised. On the one hand, the high porosity and the low water content of the freeze-dried products make the interaction between the solutes and the oxygen at the end of the process more accessible. In this way, the oxidation of bioactive compounds, such as vitamin $\mathrm{C}$, phenols or carotenoids may be promoted. On the other hand, the physical problems are related to the glass transition of the amorphous matrix, which is usually developed during the freeze-drying process. Above the glass transition temperature $(\mathrm{Tg})$, the change from the more stable glassy state to the rubbery state occurs [14]. Freeze-dried fruit pulps, as sugar-rich foods, have a low Tg value in the range of $5-15{ }^{\circ} \mathrm{C}[15,16]$. For this reason, they present collapse and other structural problems related to stickiness and caking, which begin to be developed about $20^{\circ} \mathrm{C}$ above $\operatorname{Tg}$ [14]. A usual way to delay these problems is the incorporation of high molecular weight biopolymers that contribute to an increase in $\mathrm{Tg}$, or that exert a steric role [17,18].

The disadvantage of freeze-drying is its high cost, due to the long process times and the energy cost related to the vacuum stage. For this reason, it has only been widely used to obtain products with high value added, as occurs in the pharmaceutical industries as well as in some specific food industries, such as rehydratable coffee. However, given the high sensory and functional value of fruits, associated with their high content of bioactive compounds, freeze-drying can be a niche opportunity in this case. In this sense, the technique can provide different food formats, among them, a crunchy fruit product with good consumer acceptance as a snack [18]. Despite adequate optimization of the process conditions contributing to reduce the duration of the process, several reports have indicated that both the freezing and the drying variables, such as the freezing rate or the working pressure and shelf temperature during the drying step, may affect the quality of the obtained product [18-24]. As regards the impact of increasing the shelf temperature, a study carried out with grapefruit puree indicated a decrease of more than $50 \%$ in drying time when increasing the temperature up to $40{ }^{\circ} \mathrm{C}$, without a great impact on aspects such as colour, texture or vitamin $C$ content [25]. Nor was an effect observed on the vitamin $\mathrm{C}$ content when a mandarin juice was freeze-dried at $40{ }^{\circ} \mathrm{C}$ compared to that processed at room temperature [18]. Nevertheless, the shelf temperature should not exceed either the collapse temperature or that which could cause damage to the thermolabile compounds of interest.

In this study, the impact of freeze-drying conditions on the quality of a freeze-dried orange puree with added gum Arabic and bamboo fibre was evaluated. Two freezing rates (conventional and blast freezer), three different shelf temperatures $\left(30,40,50^{\circ} \mathrm{C}\right)$ and two working pressures $(5$ and $100 \mathrm{~Pa})$ were combined. The quality indices measured were the water content, colour, porosity, mechanical properties, vitamin C, carotenoids and phenolic content, as well as the total antioxidant capacity.

\section{Materials and Methods}

\subsection{Raw Materials}

Oranges (Citrus $x$ sinensis cultivar Navel) used in this study were selected by subjective visual inspection based on a similar weight and size colour homogeneity and good physical integrity (absence of external physical damage). They were bought in October 2019 from a local supermarket in the city of Valencia (Spain) and immediately processed. Carriers used to obtain the dehydrated orange samples 
were gum Arabic (GA, Scharlab, Sentmenat, Spain) and bamboo fibre (BF, VITACEL ${ }^{\circledR}$, Rosenberg, Germany).

\subsection{Freeze-Drying Processing}

Oranges were washed, peeled, cut and triturated in a bench top electrical food processor for $40 \mathrm{~s}$ at speed 4 (2000 rpm) followed by $40 \mathrm{~s}$ at speed 9 (9100 rpm) (Thermomix TM 21, Vorwerk, Spain). The orange puree was mixed for $10 \mathrm{~min}$ at speed $3(1000 \mathrm{rpm})$ with $(5 \mathrm{~g} \mathrm{GA}+1 \mathrm{~g} \mathrm{BF}) / 100 \mathrm{~g}$ orange puree as to ensure the physical stability of the dried product [26]. The formulated orange puree (FOP) was distributed in $10.5 \times 7.8 \mathrm{~cm}$ aluminum plates of $0.5 \mathrm{~cm}$ thickness. Samples were immediately frozen at two different freezing rates (FR): slow freezing (FR-S) in a conventional freezer (Liebherr Mediline LGT 2325, Liebherr, Baden-Wurtemberg, Germany) for $48 \mathrm{~h}$ and fast freezing (FR-F), where the samples were frozen for $3 \mathrm{~h}$ at $-38{ }^{\circ} \mathrm{C}$ in a blast freezer (Hiber RDM051S, Hiber, Cernusco sul Naviglio, Italy), and then stored at $-45{ }^{\circ} \mathrm{C}$ in the conventional freezer for at least $24 \mathrm{~h}$. Frozen samples were dried in a freeze-drier (Telstar Lyoalfa-6, Telstar, Terrassa, Spain) at different pressures (P) in the chamber and shelf temperatures (T). Twelve different conditions were studied (Table 1). The shelf temperature conditioned the drying time, this being $25 \mathrm{~h}$ at $30{ }^{\circ} \mathrm{C}, 7 \mathrm{~h}$ at $40{ }^{\circ} \mathrm{C}$ and $6 \mathrm{~h}$ at $50{ }^{\circ} \mathrm{C}$. The time was selected based on preliminary experiments to be enough to achieve a water content lower than $4 \%$. At these conditions, the physical stability of the formulated puree was known to be guaranteed, as no structural collapse was observed.

Table 1. Sample and conditions code according the 12 different freeze-drying conditions studied.

\begin{tabular}{|c|c|c|c|c|c|c|c|}
\hline \multirow{2}{*}{ Sample Code } & \multicolumn{3}{|c|}{ Shelf Temperature $(\mathrm{T})$} & \multicolumn{2}{|c|}{ Pressure (P) } & \multicolumn{2}{|c|}{ Freezing Rate (FR) } \\
\hline & $30^{\circ} \mathrm{C}$ & $40{ }^{\circ} \mathrm{C}$ & $50^{\circ} \mathrm{C}$ & $5 \mathrm{~Pa}\left(\mathrm{P}_{5}\right)$ & $100 \mathrm{~Pa}\left(\mathrm{P}_{100}\right)$ & Slow (S) & Fast (F) \\
\hline $\mathrm{S} \_30 \_P_{5}$ & $x$ & & & $x$ & & $x$ & \\
\hline F_30_P & $x$ & & & $x$ & & & $x$ \\
\hline S_30_P 100 & $x$ & & & & $x$ & $x$ & \\
\hline F_30_P 100 & $x$ & & & & $x$ & & $x$ \\
\hline S_40_P 5 & & $x$ & & $x$ & & $x$ & \\
\hline F_40_P & & $x$ & & $x$ & & & $x$ \\
\hline S_40_P 100 & & $x$ & & & $x$ & $x$ & \\
\hline F_40_P 100 & & $x$ & & & $x$ & & $x$ \\
\hline S_50_P $P_{5}$ & & & $x$ & $x$ & & $x$ & \\
\hline F_50_P 5 & & & $x$ & $X$ & & & $X$ \\
\hline S_50_P 100 & & & $x$ & & $x$ & $x$ & \\
\hline F_50_P 100 & & & $x$ & & $x$ & & $x$ \\
\hline
\end{tabular}

\subsection{Water Content}

The water content $\left(\mathrm{x}_{\mathrm{w}}, \mathrm{g}\right.$ water/100 g product) of FOP was determined using the AOAC method [27]. The sample was dried in a vacuum oven (Selecta ${ }^{\circledR}$, Vaciotem-T, J.P. Selecta S.A., Barcelona, Spain) at $60 \pm 1^{\circ} \mathrm{C}$ under $P<100 \mathrm{~mm} \mathrm{Hg}$ until constant weight (XS204 DeltaRange ${ }^{\circledR}$, Mettler Toledo, Switzerland). For the freeze-dried puree, an automatic Karl Fisher titrator (Mettler Toledo, Compact Coulometric Titrator C10S, Worthington, OH, USA) was used to obtain the water content. Triplicates were performed in each case.

\subsection{Mechanical Properties}

The mechanical behaviour of the freeze-dried puree was registered using a texture analyser (TA-XT2i, Stable Micro Systems, Godalming, UK). Portions of $20 \times 20 \mathrm{~mm}$ of the freeze-dried puree were compressed using a cylindrical probe of $10 \mathrm{~mm}$ diameter, applying a strain of $80 \%$ with a test speed of $1 \mathrm{mms}^{-1}$. Six replicates were performed per sample. The parameters analysed in the test were the force required to fracture the sample (Fracture force, $\mathrm{F}_{\mathrm{f}}$ ), expressed in Newtons, and the slope 
$(\mathrm{S}, \mathrm{N} / \mathrm{mm}$ ) of the curve in the linear zone prior to fracture point, related to the sample resistance to deformation (rigidity) [28].

\subsection{Colour Measurements}

The CIE L*a*b colorimetric space was considered to characterize the colour [29]. A colorimeter (Minolta, CM 3600D, Japan) was used to measure the colour of the surface of the freeze-dried puree, taking the system observer $10^{\circ}$ and illuminant D65 as reference. Colour coordinates, $\mathrm{L}^{*}, \mathrm{a}^{*}, \mathrm{~b}^{*}$, were obtained for each freeze-dried puree. From them, the hue angle $\left(h^{*}\right.$, Equation (1)) and chroma or saturation $\left(C^{*}\right.$, Equation (2)) were obtained. When total colour differences $\left(\Delta \mathrm{E}^{*}\right)$ were calculated, Equation (3) was used. Measurements were carried out with the specular component excluded. Six replicates were performed per sample.

$$
\begin{gathered}
\mathrm{h}^{*}=\arctan \left(\mathrm{b}^{*} / \mathrm{a}^{*}\right) \\
\mathrm{C}^{*}=\left(\mathrm{a}^{* 2}+\mathrm{b}^{* 2}\right)^{0.5} \\
\Delta \mathrm{E}^{*}=\left(\left(\Delta \mathrm{L}^{*}\right)^{2}+\left(\Delta \mathrm{a}^{*}\right)^{2}+\left(\Delta \mathrm{b}^{*}\right)^{2}\right)^{1 / 2}
\end{gathered}
$$

\subsection{Porosity}

True density $(\rho)$ and apparent density $\left(\rho_{\mathrm{a}}\right)$ were obtained in order to obtain the porosity $(\varepsilon, \%)$. True density was calculated based on the sample composition (Equation (4)). Portions of the cakes were obtained with a punch of $22 \mathrm{~mm}$ diameter, and were exactly measured in height and diameter with a calliper. Apparent density of each portion was calculated from the weight (m, g; XS204 DeltaRange ${ }^{\circledR}$, Mettler Toledo, Switzerland) and corresponding volume $\left(\mathrm{V}, \mathrm{cm}_{3}\right)$ (Equation (5)). The porosity was calculated from Equation (6).

$$
\rho=\frac{1}{\frac{X_{\mathrm{w}}}{\rho_{\mathrm{w}}}+\frac{X_{\mathrm{CH}}}{\rho_{\mathrm{CH}}}}
$$

where $x_{\mathrm{w}}$ and $\mathrm{x}_{\mathrm{CH}}$ are the mass fractions of the two main components of each sample (water and carbohydrates, respectively, $x_{\mathrm{w}}$ was determined as described in Section 2.3, and $\mathrm{x}_{\mathrm{CH}}$ by difference); $\rho_{\mathrm{w}}$ and $\rho_{\mathrm{CH}}$ are their densities $\left(\rho_{\mathrm{CH}}=1.4246 \mathrm{~g} / \mathrm{cm}^{3}, \rho_{\mathrm{w}}=0.9976 \mathrm{~g} / \mathrm{cm}^{3}[30]\right)$.

$$
\begin{gathered}
\rho_{\mathrm{a}}=\frac{\mathrm{m}}{\mathrm{v}} \\
\varepsilon(\%)=100 \frac{\rho-\rho_{\mathrm{a}}}{\rho}
\end{gathered}
$$

\subsection{Total Polyphenolic Compounds}

The extraction of total phenolic compunds (TP) was carried out according to Tomás-Barberán et al. [31] with minor modifications. FOP $(2.5 \mathrm{~g})$ or freeze-dried puree $(0.5 \mathrm{~g})$ were mixed with $9 \mathrm{~mL}$ of methanol:water (70:30) using a magnetic multi-stirrer at $200 \mathrm{rpm}$ (JEIO TECH Lab Companion MS-51M, JEIO TECH Lab Companion, Seoul, Korea) under darkness and at room temperature for $30 \mathrm{~min}$. The homogenates were centrifuged at $11,515 \times \mathrm{g}$ at $4{ }^{\circ} \mathrm{C}$ for $10 \mathrm{~min}$ (GYROZEN Co., 1236R, GYROZEN, Daejeon, Korea). The supernatant was collected and analysed as to TP using the Folin-Ciocalteu method, which was adapted from Benzie et al. [32] with some modifications as described by Selvendran et al. [33]. The TP content was calculated as $\mathrm{mg}$ of gallic acid equivalents (GAE)/100 g dry basis (db) sample, using a standard curve in the range of 0-1000 ppm of gallic acid (Sigma-Aldrich, Saint Louis, MO, USA). In this study, all bioactive compounds were referred to the 
percentage (\%) of the corresponding bioactive compound preserved in the freeze-dried puree (FDP) in reference to the FOP, calculated based on Equation (7). This test was done in triplicate for each sample.

$$
\mathrm{PBc}(\%)=\frac{\mathrm{Bc}_{\mathrm{FDP}}}{\mathrm{B}_{\mathrm{FOP}}} \times 100
$$

where $\mathrm{PBC}(\%)$ is the percentage of the corresponding bioactive compound preserved; $\mathrm{Bc}_{\mathrm{FDP}}$ is the bioactive compound content in the freeze-dried puree $(\mathrm{mg} / 100 \mathrm{db})$; and $\mathrm{Bc}_{\mathrm{FOP}}$ is the bioactive compound content in the formulated orange puree $(\mathrm{mg} / 100 \mathrm{~g} \mathrm{db})$.

\subsection{Antioxidant Activity}

The antioxidant activity (AOA) was determined with the DPPH and FRAP tests. The methanolic extract obtained for the quantification of TP was used to this end. DPPH was carried out according to Brand-Williams et al. [34] with minor modification. For these samples, the steady state of the reaction was reached at $15 \mathrm{~min}$, when the absorbance at $515 \mathrm{~nm}$ was measured again. The FRAP test was carried out according to Benzie et al. [32]. The results for both methods were converted to mmol Trolox equivalents/100 $\mathrm{g} \mathrm{db}$ freeze-dried puree. The AOA was also expressed as the percentage (\%) of this activity preserved in the FDP in reference to the FOP (Equation (7)). Three replicates were performed per sample.

\subsection{Vitamin $C$}

Total vitamin C content (VC) was determined by the reduction of dehydroascorbic acid to ascorbic acid (AA) using high-performance liquid chromatography (HPLC) (Jasco, Italy). The reduction was carried out by mixing $0.5 \mathrm{~g}$ of FOP or $0.075 \mathrm{~g}$ of each of the 12 freeze-dried puree samples with 2 $\mathrm{mL}$ of a $20 \mathrm{~g} / \mathrm{L}$ DL-dithiothreitol solution (Scharlab, Spain) for $2 \mathrm{~h}$ at room temperature and under darkness [35,36]. The extraction of the mixture was carried out according to Xu et al. [37]. The HPLC conditions were: Kromaphase100-C18, $5 \mathrm{~mm}(4.6 \times 250 \mathrm{~mm})$ column (Scharlab SL); mobile phase $0.1 \%$ oxalic acid, volume injected $10 \mu \mathrm{L}$, flow rate $1 \mathrm{~mL} / \mathrm{min}$, detection at $243 \mathrm{~nm}$ (detector UV-visible MD-1510, Jasco, Cremella, Italy) at $25{ }^{\circ} \mathrm{C}$. A standard solution of L (+) ascorbic acid (Scharlab SL, Sentmenat, Spain) in the range of 5-200 ppm was prepared. The VC content was calculated as mg $\mathrm{AA} / 100 \mathrm{~g} \mathrm{db}$ sample and the percentage (\%) of this bioactive compound preserved in the FDP in reference to the FOP was calculated (Equation (7)). Three replicates were performed per sample.

\subsection{0. $\beta$-Carotene}

The extraction of $\beta$-carotene (BC) was performed using the method of Olives et al. [38] with some modifications. FOP $(0.8 \mathrm{~g})$ or freeze-dried puree $(0.2 \mathrm{~g})$ were mixed with $9 \mathrm{~mL}$ of hexane/ethanol/acetone $(50: 25: 25, v / v / v)$ using a magnetic multi-stirrer at $200 \mathrm{rpm}$ (JEIO TECH Lab Companion MS-51M, Korea), under darkness and at room temperature for $30 \mathrm{~min}$. The homogenates were centrifuged at 11,515× $\mathrm{g}$ at $4{ }^{\circ} \mathrm{C}$ for $10 \mathrm{~min}$ (GYROZEN Co., 1236R, Daejeon, Korea). Distilled water was added to the supernatant (10 mL distilled water/100 $\mathrm{mL}$ supernatant) and was manually stirred for $2 \mathrm{~min}$. The absorbance of the upper layer was measured at $446 \mathrm{~nm}$ (spectrophotometer V-1200 VWR, VWR, Radnor, PA, USA) [38]. The $\mathrm{BC}$ was calculated as mg BC/100 g db sample using a $\beta$-carotene (Dr. Ehrenstorfer, Augsburg, Germany) calibration curve in the range of $0.5-7 \mathrm{ppm}$. The $\mathrm{BC}$ was referred to the percentage (\%) of this bioactive compound preserved in the FDP in reference to the FOP (Equation (7)). Three replicates were performed per sample.

\subsection{Statistical Analysis}

Data were subjected to Partial Least Squares Regression (PLS-R) and a three way analysis of variance (ANOVA) using Tukey's HSD test to establish the significant effect of shelf temperature, pressure and freezing rate on the parameters studied, with 95\% confidence interval, by using XLSTAT 
statistical and data analysis solution (Addinsoft, 2019, Long Island, NY, USA). F-Values obtained with the ANOVA were also considered to identify the most important factors. Furthermore, a Pearson's correlation analysis between antioxidant capacity and the bioactive compounds was carried out.

\section{Results and Discussion}

All the results obtained are detailed in the Supplementary Materials (Tables S1-S3). The most relevant aspects are detailed below.

\subsection{Physicochemical Characterization}

The experimental results of the colour characterization, mechanical properties, porosity, and water content of the freeze-dried purees obtained under each of the 12 studied conditions were processed by PLS-R (Figure 1 and Table S4). Axis 1 (t1) mainly represents the impact of pressure on the qualitative explanatory variables $(\mathrm{Y})$, while axis 2 (t2) represents the impact of shelf temperature on $\mathrm{Y}$. The vectors of freezing rate are in the inner circle, which indicates that in general, these factors are not significantly correlated with the different studied properties of the samples. The variables $Y$ that are significantly affected by a specific dependent variable $(X)$ are circled in red, blue, orange and green.

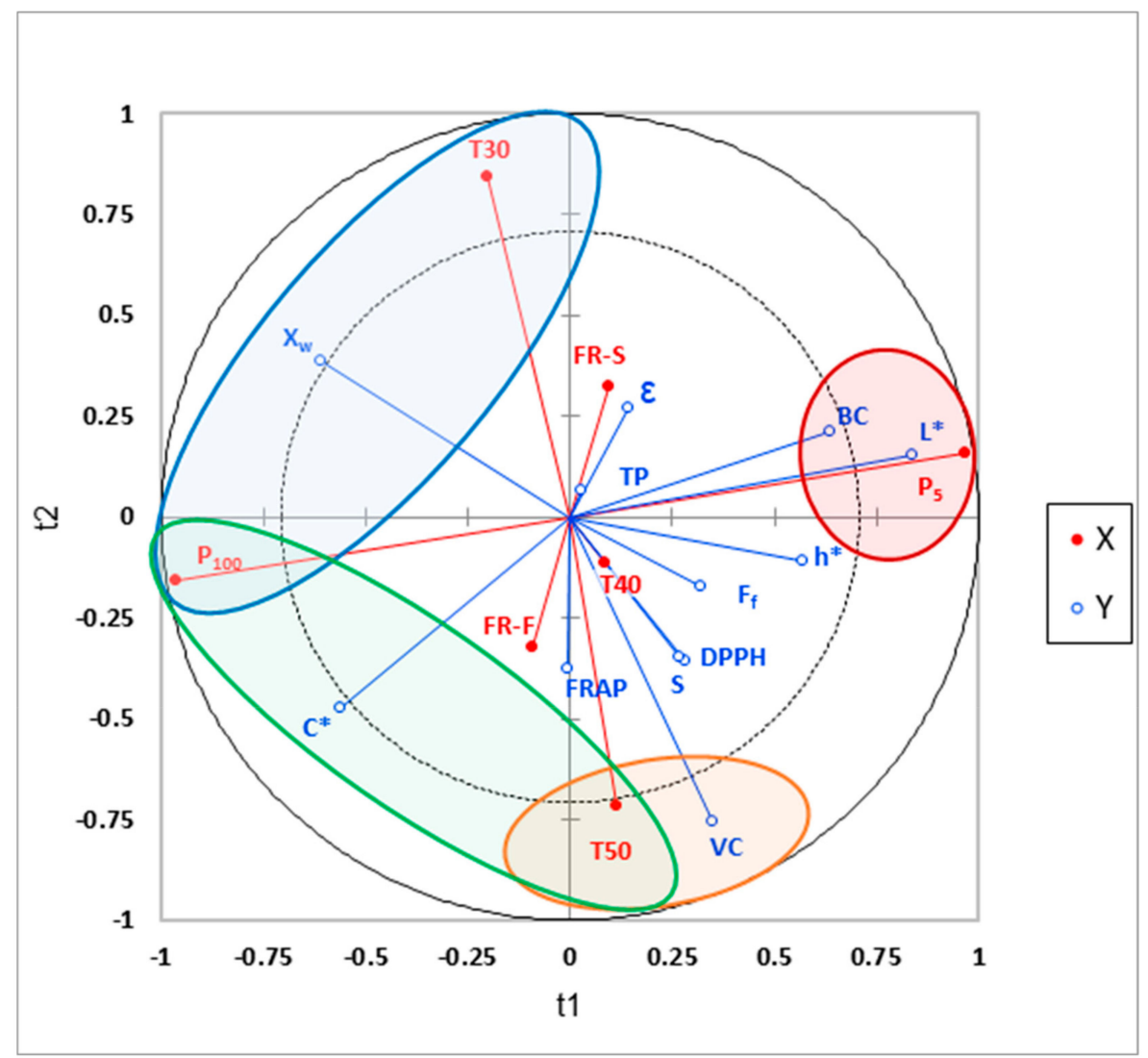

Figure 1. PLS-R projections of freeze-dried orange puree at a range or pressure, temperature and rate of freezing conditions. The dependent variables $(\mathrm{X})$ are projected in red and the qualitative explanatory variables $(\mathrm{Y})$ are projected in blue. The variables $\mathrm{Y}$ significantly correlated with a specific dependent variable are circled in red, blue, orange and green. Variables $\mathrm{X}$ : T30, T40, T50: shelf temperature applied during freeze-drying at 30,40 and $50{ }^{\circ} \mathrm{C}$, respectively; $\mathrm{P}_{5}$ and $\mathrm{P}_{100}$ : working pressures of $5 \mathrm{~Pa}$ and 100 Pa respectively; FR-S: slow freezing rate and FR-F: fast freezing rate. Variables Y: percentage (Equation (7)) of TP: total phenols, VC: vitamin C, BC: beta carotene, antioxidant activity (FRAP and DPPH); $\mathrm{F}_{\mathrm{f}}$ : fracture force $(\mathrm{N})$; S: slope related to rigidity $(\mathrm{N} / \mathrm{mm})$; $\mathrm{Xw}$ : water content (g water/100 g sample); $\varepsilon$ : porosity (\%). 


\subsubsection{Colour}

The PLS-R revealed a good correlation between pressure and $L^{*}, C^{*}, h^{*}$ values. They can be observed according to axis 1: $P_{5}$ projected on the positive side while $P_{100}$ is projected on the negative side. The external and near position of $P_{5}$ to $L^{*}$ and $P_{100}$ to $C^{*}$ denotes a significant effect of pressure on colour attributes, so that low pressure leads to a high $\mathrm{L}^{*}$ value (see red circle in Figure 1 ) while high pressure leads to a high $C^{*}$ value. Despite $h^{*}$ also being positively projected on axis 1 and so affected by pressure, its projection stays in the inner circle of the PLS-R although near the external limit. This indicates a lowered impact of the pressure on the hue angle when compared with that observed for $\mathrm{C}^{*}$ and $L^{*}$. It can also be notice that the projection of $C^{*}$ on the PLS-R, in the negative part of axis 1 and axis 2, is higher when the interaction between $P_{100}$ and T50 is considered (see green circle in Figure 1). The shorter freeze-drying process carried out at $50{ }^{\circ} \mathrm{C}$ contributes to promoting freeze-dried products with a higher value of chroma. In addition, $\mathrm{C}^{*}$ is projected in the same side of the fast freezing rate (FR-F), the last one being in the inner circle (poorly correlated according to axis 2).

These observations were confirmed by the ANOVA, as values of $\mathrm{L}^{*}, \mathrm{C}^{*}$ and $\mathrm{h}^{*}$ of the samples were significantly affected by working pressure $(p<0.05)$. Further, $C^{*}$ was also affected by the interaction between shelf temperature and freezing rate $(p<0.05)$, but with a low F-Value (7.86). Taking into account the significances shown by the PLS-R analysis and the F-Values of the ANOVA, Figure 2 was constructed, showing $L^{*}$ and $C^{*}$ values of the samples obtained at the different pressure and shelf temperature and considering the mean value at both freezing rates. When working with the highest pressure during freeze-drying $\left(\mathrm{P}_{100}\right)$, the samples showed lower values of $\mathrm{L}^{*}$ and higher $\mathrm{C}^{*}$, which means a darker and saturated colour. In this case, the chroma is specially enhanced at a higher temperature in the freeze-drier shelves, either $40^{\circ} \mathrm{C}$ or $50{ }^{\circ} \mathrm{C}$ (Figure $2, p<0.05$ ). The hue angle, with values between 80.3 and 82.6, showed a lower value when working with high pressure and freeze-drier shelves temperature below $50{ }^{\circ} \mathrm{C}(p<0.05)$. Similar results have been reported by Hammami et al. [22], who noted a slight $L^{*}$ decrease when working at higher pressures $(P>108 \mathrm{~Pa})$ for strawberries pieces, which was related to the pronounced shrinkage observed under these conditions. Different authors found that the operating working pressure should be lower than $50 \mathrm{~Pa}$ to avoid shrinkage for strawberries pieces and banana slides [22]. With regards to shelf temperature, increasing temperature may cause some slight sugar browning reactions like non-enzymatic or Maillard reactions, which means a reinforcement of the colour shown by the increase in $C^{*}$. Nevertheless, it is better detected in shrunken samples due to its different optical light reflection capacity [22]. 


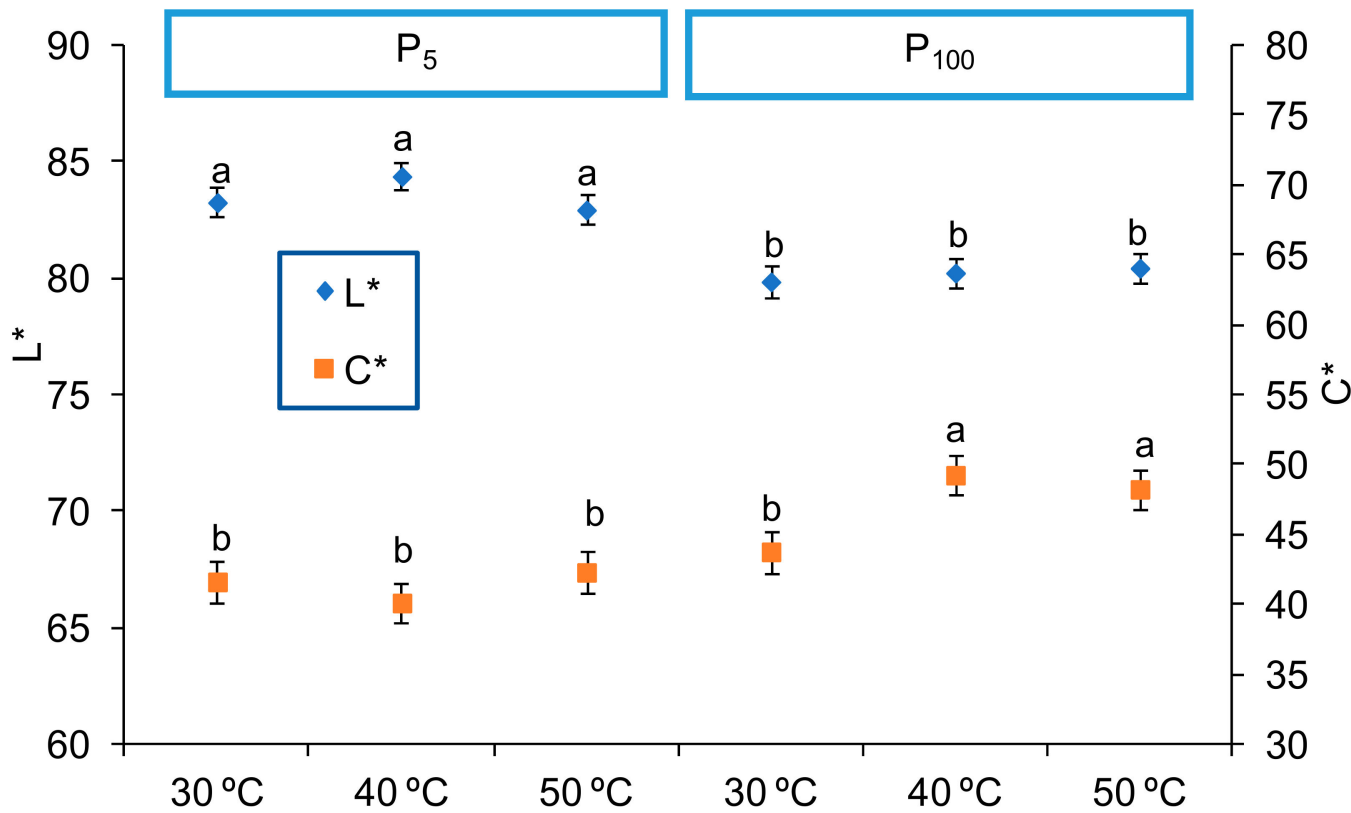

Figure 2. Values (mean and Tukey's HSD) of $\mathrm{L}^{*}$ in left axis and $\mathrm{C}^{*}$ in right axis of the freeze-dried purees according to the interaction between shelf temperature $\left(30,40\right.$ or $\left.50{ }^{\circ} \mathrm{C}\right)$ and pressure $\left(\mathrm{P}_{5}: 5 \mathrm{~Pa}\right.$ and $\mathrm{P}_{100}: 100 \mathrm{~Pa}$ ) factors. Different letters for each attribute indicate different homogeneous groups for the Temperature*Pressure interaction $(p<0.05)$. Data of both freezing rates are considered in the mean values.

According to the PLS-R and the ANOVA, pressure and shelf temperature were the factors that had a significant impact on the colour. The total differences in colour were calculated in order to evaluate the impact of both factors on the colour. Regarding the shelf temperature, values of $\Delta \mathrm{E}^{*}$ between 1.11 and 5.51 were obtained, while the range was 4.45-9.98 for the pressure influence. According to Bodart et al. [39], total differences in colour are not obvious to the human eyes when $\Delta \mathrm{E}^{*}<1$, minor colour differences could be appreciated by the human eye depending on the hue when $1<\Delta \mathrm{E}^{*}<3$ and visually obvious changes for human eyes occur when $\Delta \mathrm{E}^{*}>3$. Therefore, it seems that pressure has a greater effect than the other factors on the colour.

\subsubsection{Structure}

Freeze-dried purees showed high porosity, typical of freeze-dried products, with values ranging from $86.4-87.4 \%$. The PLS-R indicated a correlation between FR-S and porosity (mainly projected in the positive side of axis 2, Figure 1), which means that a slow rate of freezing leads to bigger ice crystals and so a bigger expansion of gas cells in the structure (higher porosity) during the freeze-drying process. Nevertheless, they are in the inner circle, which means the effect is not significant. In fact, according to ANOVA, porosity of the samples was not significantly affected by any factor evaluated $(p>0.05)$.

As a result of the mechanical analysis, the force versus distance curves were obtained for each sample freeze-dried under each of the 12 conditions (Figure 3). The linear regression of the first part of the curve was taken to calculate the slope before $F_{f}$, related to the rigidity of the sample. As can be observed in the PLS-R (Figure 1), factors T50 and rigidity are both partially correlated and projected on the negative side of axis 2 , which means that a higher temperature leads to an increase in the rigidity of the freeze-dried samples. However, because the rigidity is projected in the inner circle, it indicates a moderate positive correlation. In regards to the ANOVA results, the shelf temperature had a significant effect on the rigidity (slope) of the freeze-dried samples $(p<0.05)$; however, its low F-Value (8.65) makes it possible to confirm its low significance. 


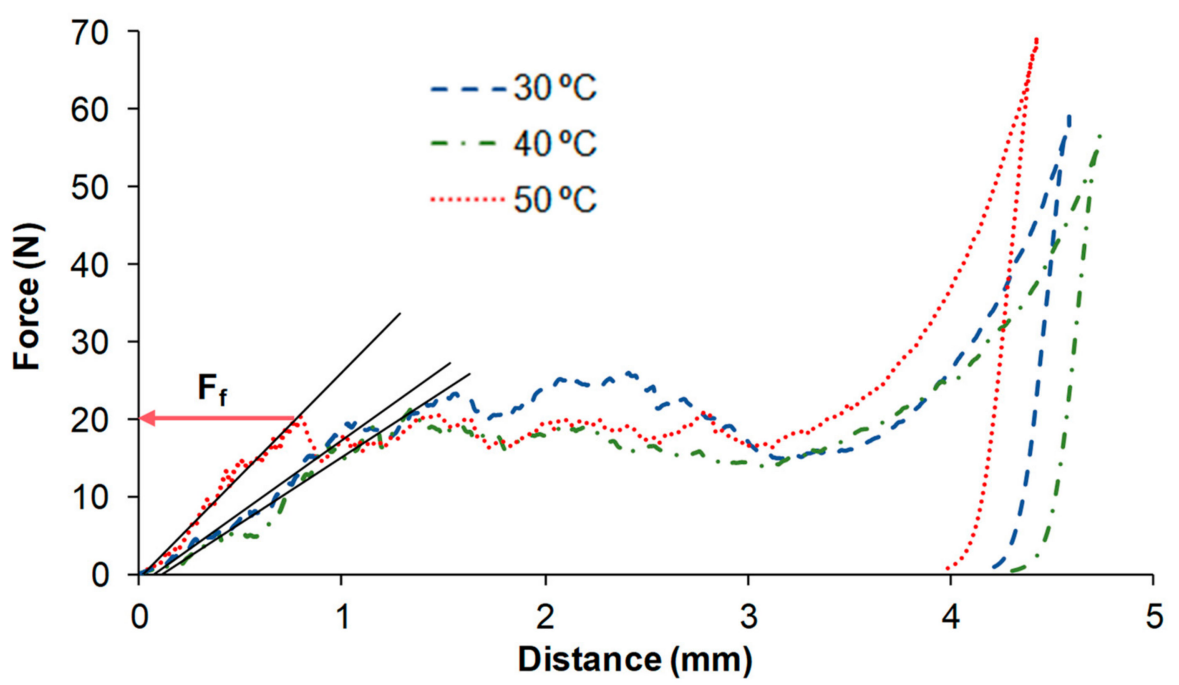

Figure 3. Examples of force-distance curves obtained from the freeze-dried purees frozen at a slow rate and freeze-dried at $5 \mathrm{~Pa}$, and with different shelf temperatures $\left(30,40\right.$ and $\left.50^{\circ} \mathrm{C}\right) . \mathrm{F}_{\mathrm{f}}$ : fracture force.

Values of the slope $18-26 \mathrm{~N} / \mathrm{mm}$ were obtained when heating the freeze-drier shelves to $50{ }^{\circ} \mathrm{C}$, as compared to $11-18 \mathrm{~N} / \mathrm{mm}$ values obtained at 30 and $40{ }^{\circ} \mathrm{C}$. As a greater slope indicates less deformation of the sample by exerting an effort on it, it can be concluded that freeze-drying heating the shelves to $50{ }^{\circ} \mathrm{C}$ promotes the mechanical rigidity of the freeze-dried samples before they fracture. This can be considered desirable as it would be related to a higher mechanical resistance of the sample during its handling before consumption.

Fracture force of all the samples varied between $12.1 \pm 1.6 \mathrm{~N}$ and $19 \pm 5 \mathrm{~N}$. The PLS-R revealed a moderate positive correlation between fracture force and both lower pressure $\left(\mathrm{P}_{5}\right)$ (both projected in the positive side of axis 1 ) and T50 (both projected in the negative side of axis 2). This means that working with lower pressure and higher temperature seems to promote a freeze-dried puree that is more resistant to fracture. According to the ANOVA, neither the temperature nor the freezing rate showed a significant effect on the fracture force $(p>0.05)$. The pressure did show $p<0.05$, but again, with a very low $F$-Value (7.17).

The water content of the samples ranged between $2.2 \pm 0.3$ and $4.2 \pm 0.2 \mathrm{~g}$ water $/ 100 \mathrm{~g}$ sample. The PLS-R indicated a high correlation between water content $(\%)$, high pressure $\left(\mathrm{P}_{100}\right)$ and low temperature (T30), circled in blue colour in Figure 1. In fact, this statement was confirmed by the ANOVA that indicated a significant effect on the final water content of the freeze-dried samples by the shelf temperature and the pressure $(p<0.05)$. In this way, drying at the highest pressure (100 Pa) and the lowest shelf temperature $\left(30^{\circ} \mathrm{C}\right)$ promoted samples with the highest water content. On the other hand, Figure 1 shows a clear negative correlation between water content and fracture force, which means the smaller the water content of the freeze-dried samples, the greater the mechanical resistance to fracture. In this case, the final water content of the samples was lower than $4.2 \%$. However, it seems that small changes outside this range, related to working conditions, will have an important impact on the mechanical properties of the sample.

\subsection{Bioactive Compounds}

The quantification of total phenols, vitamin $C, \beta$-carotene, and antioxidant activity evaluated by two methods (FRAP and DPPH), was carried out in the FOP and after being freeze-dried for each of the 12 conditions evaluated.

The PLS-R indicated that TP is not projected on the bi-plot (Figure 1), which means that it is relatively less impacted than the other bioactive compounds (TP vector very close to the origin 0.0 ). In fact, according to the ANOVA, the TP was not affected by working pressure and freezing rate $(p>0.05)$ and was better preserved when the freeze-drying was carried out at 30 or $50^{\circ} \mathrm{C}$ as compared to $40{ }^{\circ} \mathrm{C}$ 
$(p<0.05)$, despite the temperature factor also having a low F-Value (8.07). In fact, the most marked difference was observed with the factor temperature, which was $5 \%$ of preservation between 30 and 40 ${ }^{\circ} \mathrm{C}$ (Figure 4). No significant interactions between the factors were observed $(p>0.05)$.

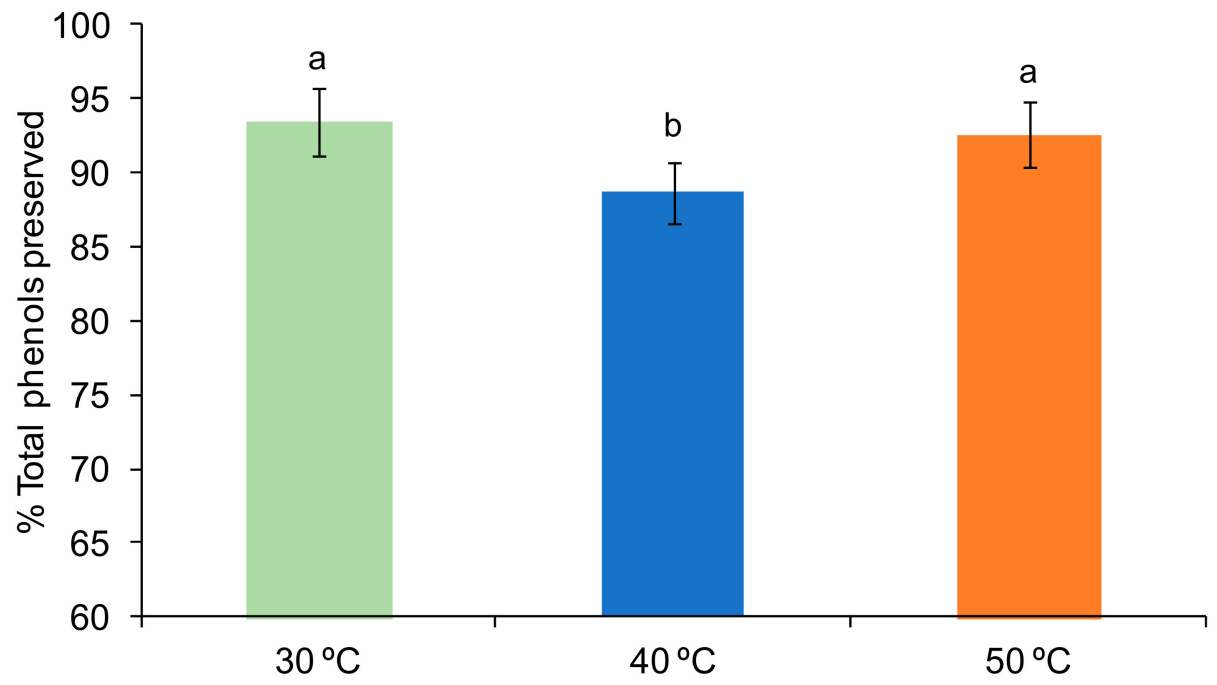

Figure 4. Percentage (\%) of preserved total phenols (mean and Tukey's HSD) of samples according to the shelf temperature factor $\left(30,40\right.$ or $\left.50^{\circ} \mathrm{C}\right)$. Different letters indicate different homogeneous groups for the shelf temperature factor $(p<0.05)$. Data of both freezing rates and both pressures are considered in the mean values.

Figure 4 shows TP preservation by shelf temperature, considering both freezing rates and pressures in the mean values. It seems that TP may be affected by the ratio of time and temperature of processing, as reported by other authors [40]. In this case, mild $40^{\circ} \mathrm{C}$ heating for more than $7 \mathrm{~h}$ seems to compromise TP preservation.

The presence of VC in the final product is used as a reference of high nutritional quality for the different industrial processes, due to its relative instability to heat, oxygen and light [41,42]. The impact of temperature on VC can be clearly observed on the PLS-R according to axis 2 (Figure 1). Vector T50 and T40 are projected in the same direction (negative side of axis 2), while T30 is anti-correlated to them (projected on the positive side of axis 2). This confirms that a higher shelf temperature along the process preserved the vitamin $C$ of the samples. According to the ANOVA, it can be confirmed that VC was affected by the shelf temperature and the pressure during freeze-drying (Figure 5, $p<0.05$ ). A significant interaction between both factors indicated that heating the freeze-drier shelves to 40 or $50^{\circ} \mathrm{C}$ promoted samples with higher vitamin $\mathrm{C}$ content than those freeze-dried at $30^{\circ} \mathrm{C}$. Despite $\mathrm{VC}$ being reported to have thermal stability [41], the length of time required when the freeze-drying is carried out at $30{ }^{\circ} \mathrm{C}(25 \mathrm{~h})$ may cause VC loss. However, the lower content of VC of samples freeze-dried at $30{ }^{\circ} \mathrm{C}$ was even lower when higher pressure was applied (Figure 5). This means that for a long expected process time, oxygen presence should be maximally avoided. 


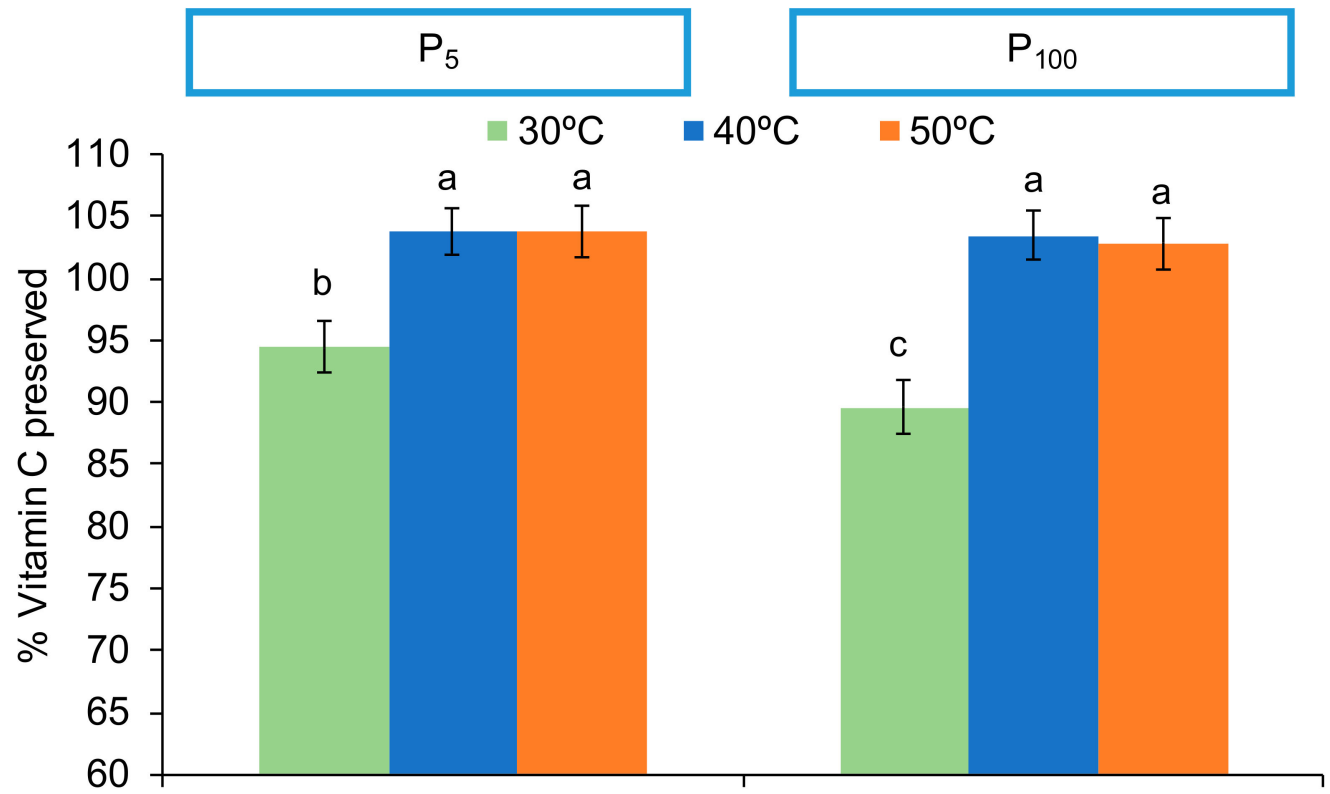

Figure 5. Percentage (\%) of preserved vitamin C (mean and Tukey's HSD) according to the interaction between shelf temperature $\left(30,40\right.$ or $\left.50^{\circ} \mathrm{C}\right)$ and pressure $\left(\mathrm{P}_{5}: 5 \mathrm{~Pa}\right.$ and $\left.\mathrm{P}_{100}: 100 \mathrm{~Pa}\right)$ factors. Different letters indicate different homogeneous groups for the temperature* pressure interaction $(p<0.05)$. Data of both freezing rates are considered in the mean values.

Certain carotenoids are highly coloured compounds that also exhibit provitamin A activity. BC has the highest vitamin A activity [43]. The PLS-R (Figure 1) underlined, in particular, the BC preservation by low pressure, as it is projected on the positive side of axis 1 and highly correlated with vector $\mathrm{P}_{5}$. In this case, the ANOVA indicated a significant effect of the three factors considered $(p<0.05$, Figure 6$)$, the higher the pressure, the higher the temperature, and the slower the freezing rate, the greater the loss of BC. Nevertheless, the F-Values were 88,6 and 6 for pressure, shelf temperature and freezing rate, respectively. Again, a low F-Value in the ANOVA is correlated with no significant effect detected by the PLS-R analysis. However, the ANOVA also revealed a significant interaction between the pressure and both the shelf temperature and the freezing rate $(p<0.05)$. Figure 6 shows the interaction of pressure and shelf temperature for each FR.

According to these interactions, the pressure effect is no longer significant at $50{ }^{\circ} \mathrm{C}$, when a significant part of $\mathrm{BC}$ has already been degraded by the effect of the shelf temperature. In addition, the effect of the shelf temperature was not significant at higher pressure. Furthermore, when almost no oxygen is present $\left(\mathrm{P}_{5}\right), \mathrm{BC}$ is conserved quite well, regardless of freezing rate. It is in the greater presence of oxygen $\left(\mathrm{P}_{100}\right)$ when the effect of the freezing rate is significant in relation to the better preservation of BC at the FR-F. From the ANOVA results, the PLS-R analysis can be nuanced in the sense that the most recommendable way to keep the maximum carotenoids present in the orange puree during freeze-drying is when the drying stage is carried out at the lowest pressure studied and heating the freeze-dryer shelves to 30 or $40^{\circ} \mathrm{C}$, without the freezing-rate being relevant in this case. 


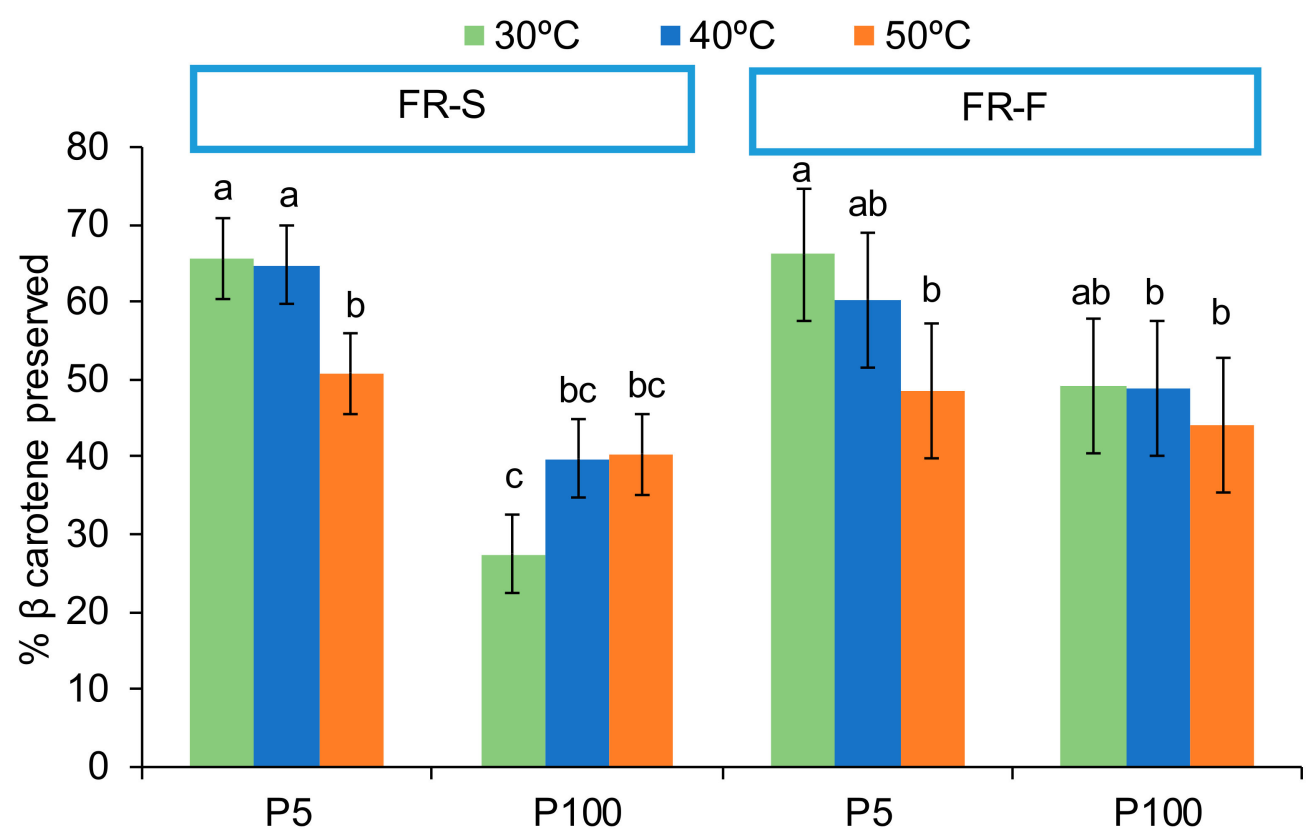

Figure 6. Percentage (\%) of preserved $\beta$-carotene (mean and Tukey's HSD) according to the interaction between shelf temperature $\left(30,40\right.$ or $\left.50{ }^{\circ} \mathrm{C}\right)$ and pressure $\left(\mathrm{P}_{5}: 5 \mathrm{~Pa}\right.$ and $\left.\mathrm{P}_{100}: 100 \mathrm{~Pa}\right)$ factors for each freezing-rate (FR-S and FR-F: slow and fast freezing rates, respectively). Different letters indicate different homogeneous groups for the temperature* pressure interaction for both freezing-rate independently $(p<0.05)$.

As regards antioxidant activity, values of DPPH between $86.5 \pm 1.8 \%$ and $94.3 \pm 1.5 \%$ were observed. The PLS-R revealed that the vector DPPH is projected on the lower right corner of the graph, which means a moderate positive correlation with both the lowest pressure and the highest temperature. According to the ANOVA analysis, no significant effect of pressure was detected $(p>0.05)$. Although freeze-drying carried out at $30^{\circ} \mathrm{C}$ leads to samples with lower DPPH than those processed at $40{ }^{\circ} \mathrm{C}$ or $50{ }^{\circ} \mathrm{C}(\mathrm{p}<0.05)$, once again, with a low F-Value (9.51) for shelf temperature factor. On the other hand, FRAP values between $91 \pm 2 \%$ and $103 \pm 6 \%$ of preservation for all the conditions studied were analysed. Neither the PLS-R nor the ANOVA analysis showed a significant effect of any of the freeze-drying process variables on FRAP $(p>0.05)$.

From the Pearson correlation, only a significant and positive correlation $(0.5774, p<0.05)$ was obtained between values of DPPH and vitamin C. Despite AOA being correlated in a positive way with the total phenolic, vitamin $C$ content and carotenoids, it has been suggested that VC contributes to antioxidant capacity more than others antioxidant constituents, such as phenols or carotenoid in fruits with high VC content [41,44]. This can also be observed on the PLS-R projection as VC, DPPH and FRAP are projected on the same direction.

\section{Conclusions}

In conclusion, the optimum freeze-drying conditions for preserving the nutrients considered in this study and with interesting structural properties of the obtained product, as to be perceived as crunchy by the consumers, are low pressure $(5 \mathrm{~Pa})$ and high shelf temperature $\left(50{ }^{\circ} \mathrm{C}\right)$. These conditions also promote freeze-dried puree with a clear, yellowish and less saturated colour. The fact that a lower degradation of nutrients was observed at higher temperatures may be explained by the great reduction $(75 \%)$ of the duration of freeze-drying process at $50{ }^{\circ} \mathrm{C}$, and the mild temperatures used. The shorter exposure of nutrients to a minimal presence of oxygen in a high porous matrix is less favourable to oxidation/degradation reactions and contributes to the preservation of nutrients. As regards to the statistical analysis of the data obtained in this study, PLS-R projection may be recommended against 
ANOVA as an easier tool to detect the most important factors and interactions to be considered for freeze-drying process optimization. ANOVA allows a more precise analysis, though less practical.

Supplementary Materials: The following are available online at http://www.mdpi.com/2304-8158/9/1/32/s1, Table S1: Values (mean \pm SD) of the different physicochemical properties evaluated. All acronyms used are described in the main text. Table S2: Percentage (mean \pm SD) of the bioactive compounds preserved in the FDP for each condition evaluated. All acronyms used are described in the main text. Table S3: Values (mean and Tukey'HSD classification) of the different physicochemical properties and bioactive compounds evaluated for: each individual factor $(\mathrm{a}-\mathrm{c})$, the interaction between two different factors $(\mathrm{d}-\mathrm{f})$ and for the interaction between the three factors studied (g). All acronyms used are described in the main text. Table S4: Variable importance in the PLS-R Projection (VIP). VIP > 1 are considered as the most important variables for the model. All acronyms used are described in the main text.

Author Contributions: Conceptualization: M.A.S.-E., M.d.M.C. and N.M.-N.; Data curation: M.A.S.-E. and M.d.M.C.; Formal analysis: M.A.S.-E., C.A. and N.M.-N.; Funding acquisition: M.A.S.-E., M.d.M.C. and N.M.-N.; Investigation: M.A.S.-E., M.d.M.C. and N.M.-N.; Methodology: M.A.S.-E., C.A., M.d.M.C. and N.M.-N.; Project Administration: M.d.M.C. and N.M.-N.; Supervision, N.M.-N.; Writing-original draft: M.A.S.-E., C.A., and N.M.-N.; Writing-review and editing: M.A.S.-E., C.A., T.F., and N.M.-N. All authors have read and agreed to the published version of the manuscript.

Funding: This research was funded by Ministerio de Economía y Competitividad of Spain [AGL 2017-89251] and by Ministerio de Educación of Spain [FPU14/02633].

Acknowledgments: The authors thank the Ministerio de Economía y Competitividad of Spain for the financial support given through the Project AGL 2017-89251 and the Ministerio de Educación of Spain for the FPU grant (FPU14/02633) awarded to Ms. Andrea Silva.

Conflicts of Interest: The authors declare no conflict of interest.

\section{References}

1. Poulose, S.M.; Harris, E.D.; Patil, B.S. Citrus Limonoids Induce Apoptosis in Human Neuroblastoma Cells and Have Radical Scavenging Activity. J. Nutr. 2005, 135, 870-877. [CrossRef] [PubMed]

2. Kader, A.A. Flavor Quality of Fruits and Vegetables. J. Sci. Food Agric. 2008, 88, 1863-1868. [CrossRef]

3. De Ancos, B.; Gónzalez, E.M.; Cano, M.P. Ellagic Acid, Vitamin C, and Total Phenolic Contents and Radical Scavenging Capacity Affected by Freezing and Frozen Storage in Raspberry Fruit. J. Agric. Food Chem. 2000, 48, 4565-4570. [CrossRef] [PubMed]

4. Aschoff, J.K.; Kaufmann, S.; Kalkan, O.; Neidhart, S.; Carle, R.; Schweiggert, R.M. In Vitro Bioaccessibility of Carotenoids, Flavonoids, and Vitamin C from Differently Processed Oranges and Orange Juices [Citrus sinensis (L.) Osbeck]. J. Agric. Food Chem. 2015, 63, 578-587. [CrossRef] [PubMed]

5. Gökmen, V.; Kahraman, N.; Demir, N.; Acar, J. Enzymatically Validated Liquid Chromatographic Method for the Determination of Ascorbic and Dehydroascorbic Acids in Fruit and Vegetables. J. Chromatogr. A 2000, 881, 309-316. [CrossRef]

6. Peterson, J.; Dwyer, J.; Beecher, G.; Bhagwat, S.A.; Gebhhardt, S.E.; Haytowitz, D.B.; Holden, J.M. Flavanones in Oranges, Tangerines (Mandarins), Tangors, and Tangelos: A Compilation and Review of the Data from the Analytical Literature. J. Food Compos. Anal. 2006, 19, 66-73. [CrossRef]

7. Ramful, D.; Tarnus, E.; Aruoma, O.I.; Bourdon, E.; Bahorun, T. Polyophenol Composition, Vitamin C Content and Antioxidant Capacity of Mauritian Citrus Fruit Pulps. Food Res. Int. 2011, 44, 2088-2099. [CrossRef]

8. Goulas, V.; Manganaris, G.A. Exploring the Phytochemical Content and the Antioxidant Potential of Citrus Fruits Grown in Cyprus. Food Chem. 2012, 131, 39-47. [CrossRef]

9. Moreiras, O.; Carbajal, A.; Cabrera, L.; Cuadrado, C. Tablas de Composición de los Alimentos; Pirámide Editions: Madrid, Spain, 2018; pp. 52-53.

10. Institute of Medicine. Dietary Reference Intakes for Vitamin C, Vitamin E, Selenium, and Carotenoids; The National Academies Press: Washington, DC, USA, 2000; p. 507.

11. Fazaeli, M.; Emam-Djomeh, Z.; Kalbasi-Ashtari, A.; Omid, M. Effect of Process Conditions and Carrier Concentration for Improving Drying Yield and other Quality Attributes of Spray Dried Black Mulberry (Morus nigra) Juice. Int. J. Food Eng. 2012, 8, 1-20. [CrossRef]

12. Barbosa-Canovas, G.; Ortega-Rivas, E.; Juliano, P.; Yan, H. Food Powders: Physical Properties, Processing and Functionality; Kluwer Academic/Plenum Publisher: New York, NY, USA, 2005; pp. 271-304. 
13. Karam, M.C.; Petit, J.; Zimmer, D.; Baudelaire, E. Effects of Drying and Grinding in Production of Fruit and Vegetable Powders. A Review. J. Food Eng. 2016, 188, 32-49. [CrossRef]

14. Roos, Y.H. Phase Transitions in Food; Academic Press: San Diego, CA, USA, 1995; pp. $19-47$.

15. Silva, M.A.; Sobral, P.J.A.; Kieckbusch, T.G. State Diagrams of Freeze-Dried Camu-Camu (Myrciaria dubia (HBK) Mc Vaugh) Pulp with and without Maltodextrin Addition. J. Food Eng. 2006, 77, 426-432. [CrossRef]

16. Conceição, M.C.; Fernandes, T.N.; de Resende, J.V. Stability and Microstructure of Freeze-Dried Guava Pulp (Psidium guajava, L.) with Added Sucrose and Pectin. J. Food Sci. Technol. 2016, 53, 2654-2663. [CrossRef] [PubMed]

17. Telis, V.R.N.; Martínez-Navarrete, N. Biopolymers Used as Drying Aids in Spray- Drying and Freeze-Drying of Fruit Juices and Pulps. In Biopolymer Engineering in Food Processing; Telis, V.N.N., Ed.; CRC Press: Boca Raton, FL, USA, 2012; pp. 279-325.

18. Martínez-Navarrete, N.; Salvador, A.; Oliva, C.; Camacho, M.M. Influence of Biopolymers and Freeze-Drying Shelf Temperature on the Quality of a Mandarin Snack. LWT 2019, 99, 57-61. [CrossRef]

19. Genin, N.; Rene, F. Influence of Freezing Rate and the Ripeness State of Fresh Courgette on the Quality of Freeze-Dried Products and Freeze-Drying Time. J. Food Eng. 1996, 29, 201-209. [CrossRef]

20. Karel, M.; Flink, J.M. Influence of Frozen State Reactions on Freeze-Dried Foods. J. Agric. Food Chem. 1973, 21, 16-21. [CrossRef]

21. Ceballos, A.M.; Giraldo, G.I.; Orrego, C.E. Effect of Freezing Rate on Quality Parameters of Freeze-Dried Soursop Fruit Pulp. J. Food Eng. 2012, 111, 360-365. [CrossRef]

22. Hammami, C.; René, F. Determination of Freeze-Drying Process Variables for Strawberries. J. Food Eng. 1997, 32, 133-154. [CrossRef]

23. Lombraña, J.I. The Influence of Pressure and Temperature on Freeze-Drying in an Adsorbent Medium and Establishment of Drying Strategies. Food Res. Int. 1997, 30, 213-222. [CrossRef]

24. Ratti, C. Hot Air and Freeze-Drying of High-Value Foods: A Review. J. Food Eng. 2001, 49, 311-319. [CrossRef]

25. Egas-Astudillo, L.A.; Silva, A.; Uscanga, M.; Martínez-Navarrete, N.; Camacho, M.M. Impact of Shelf Temperature on Freeze-Drying Process and Porosity Development. In Proceedings of the 21st International Drying Symposium (IDS’ 2018), Valencia, Spain, 11-14 September 2018; pp. 843-850.

26. Agudelo, C.; Igual, M.M.; Camacho, M.M.; Martínez-Navarrete, N. Effect of Process Technology on the Nutritional, Functional, and Physical Quality of Grapefruit Powder. Food Sci. Technol. Int. 2016, 23, 61-74. [CrossRef]

27. Association of Official Analytical Chemists (AOAC). Official Methods of Analysis; Association of Official Analytical Chemists: Arlington, VA, USA, 1990; pp. 931-935.

28. Contreras, C.; Martín-Esparza, M.E.; Chiralt, A.; Martínez-Navarrete, N. Influence of Microwave Application on Convective Drying: Effects on Drying Kinetics, and Optical and Mechanical Properties of Apple and Strawberry. J. Food Eng. 2008, 88, 55-64. [CrossRef]

29. Hutchings, J.B. Food Colour and Appearance; Blackie Academic \& Professional: Glasglow, UK, 1999; pp. $199-235$.

30. Okos, M.R. Physical and Chemical Properties of Food; American Society of Agricultural Engineers: Saint Joseph, MI, USA, 1986; pp. 35-77.

31. Tomás-Barberán, F.A.; Gil, M.; Cremin, P.; Waterhouse, A.L.; Hess-Pierce, B.; Kader, A.A. HPLC-DAD-ESIMS Analysis of Phenolic Compounds in Nectarines, Peaches, and Plums. J. Agric. Food Chem. 2001, 49, 4748-4760. [CrossRef] [PubMed]

32. Benzie, I.F.F.; Strain, J.J. Ferric Reducing/Antioxidant Power Assay: Direct Measure of Total Antioxidant Activity of Biological Fluids and Modified Version for Simultaneous Measurement of Total Antioxidant Power and Ascorbic Acid Concentration. Methods Enzymol. 1999, 299, 15-27. [CrossRef] [PubMed]

33. Selvendran, R.R.; Ryden, P. Methods in Plant Biochemistry. In Carbohydrates; Dey, P.M., Ed.; Academic Press: London, UK, 1990; p. 549.

34. Brand-Williams, W.; Cuvelier, M.E.; Berset, C. Use of a Free Radical Method to Evaluate Antioxidant Activity. LWT Food Sci. Technol. 1995, 28, 25-30. [CrossRef]

35. Sánchez-Mata, M.C.; Cámara-Hurtado, M.; Díez-Marqués, C.; Torija-Isasa, M.E. Comparison of High-Performance Liquid Chromatography and Spectrofluorimetry for Vitamin C Analysis of Green Beans (Phaseolus vulgaris, L.). Eur. Food Res. Technol. 2000, 210, 220-225. [CrossRef] 
36. Sánchez-Moreno, C.; Plaza, L.; De Ancos, B.; Cano, M.P. Quantitative Bioactive Compounds Assessment and Their Relative Contribution to the Antioxidant Capacity of Commercial Orange Juices. J. Sci. Food Agric. 2003, 83, 430-439. [CrossRef]

37. Xu, B.J.; Chang, S.K.C. A Comparative Study on Phenolic Profiles and Antioxidant Activities of Legumes as Affected by Extraction Solvents. J. Food Sci. 2007, 72, 159-166. [CrossRef]

38. Olives, A.I.; Cámara, M.; Sánchez, M.C.; Fernández, V.; López, M. Application of a UV-Vis Detection-HPLC Method for a Rapid Determination of Lycopene and $\beta$-Carotene in Vegetables. Food Chem. 2006, 95, 328-336. [CrossRef]

39. Bodart, M.; de Peñaranda, R.; Deneyer, A.; Flamant, G. Photometry and Colorimetry Characterisation of Materials in Daylighting Evaluation Tools. Build. Environ. 2008, 43, 2046-2058. [CrossRef]

40. Obied, H.K.; Bedgood, D.R.; Prenzler, P.D.; Robards, K. Effect of Processing Conditions, Prestorage Treatment, and Storage Conditions on the Phenol Content and Antioxidant Activity of Olive Mill Waste. J. Agric. Food Chem. 2008, 56, 3925-3932. [CrossRef]

41. Igual, M.; García-Martínez, E.; Camacho, M.M.; Martínez-Navarrete, N. Effect of Thermal Treatment and Storage on the Stability of Organic Acids and the Functional Value of Grapefruit Juice. Food Chem. 2010, 118, 291-299. [CrossRef]

42. Lin, T.M.; Durance, T.D.; Scaman, C.H. Characterization of Vacuum Microwave, Air and Freeze Dried Carrot Slices. Food Res. Int. 1998, 31, 111-117. [CrossRef]

43. Fisher, J.F.; Rouseff, R.L. Solid-Phase Extraction and HPLC Determination of $\beta$-Cryptoxanthin and $\alpha$ - and $\beta$-Carotene in Orange Juice. J. Agric. Food Chem. 1986, 34, 985-989. [CrossRef]

44. Tavarini, S.; Degl'Innocenti, E.; Remorini, D.; Massai, R.; Guidi, L. Antioxidant Capacity, Ascorbic Acid, Total Phenols and Carotenoids Changes during Harvest and after Storage of Hayward Kiwifruit. Food Chem. 2008, 107, 282-288. [CrossRef]

(C) 2019 by the authors. Licensee MDPI, Basel, Switzerland. This article is an open access article distributed under the terms and conditions of the Creative Commons Attribution (CC BY) license (http://creativecommons.org/licenses/by/4.0/). 